\title{
Predicting Adverse Outcomes in Lower Respiratory Tract Infections
}

\author{
Spencer S. Conte, DO, Grant Family Medicine; Michael E. Jobansen, MD, MS, Associate Editor \\ Ann Fam Med 2019;17(3):iii. https://doi.org/10.1370/afm.2400.
}

The Annals of Family Medicine encourages readers to develop a learning community to improve health care and health through enhanced primary care. Participate by conducting a RADICAL journal club. RADICAL stands for Read, Ask, Discuss, Inquire, Collaborate, Act, and Learn. We encourage diverse participants to think critically about important issues affecting primary care and act on those discussions. ${ }^{1}$

\section{HOW IT WORKS}

In each issue, the Annals selects an article and provides discussion tips and questions. Take a RADICAL approach to these materials and post a summary of your conversation in our online discussion. (Open the article and click on "TRACK Discussion/ Submit a comment.") Discussion questions and information are online at: http://www.annfammed.org/site/AJC/.

\section{CURRENT SELECTION}

\section{Article for Discussion}

Moore M, Stuart B, Little $\mathrm{P}$, et al. Predictors of adverse outcomes in uncomplicated lower respiratory tract infections. Ann Fam Med. 2019;17(3):231-238.

\section{Discussion Tips}

Acute lower respiratory tract infections are common in primary care. This article uses a prospective cohort design to predict the likelihood that patients will have a serious adverse outcome (late-onset pneumonia, hospitalization, death). Consider how this study could influence the care you provide to patients with lower respiratory tract infections (eg, closer follow-up, antibiotics).

\section{Discussion Questions}

- What question is asked by this study and why does it matter?

- What is a prospective cohort study? How does it differ from a retrospective cohort study? What advantages and disadvantages does this design allow?

- What was the predicted outcome? Could the out- comes have been grouped together? How were variables selected for inclusion in the prediction model?

- What variables were included in the final model to predict adverse outcomes? Could others have been included (eg, including unmeasured variables)?

- What are discrimination and calibration? Why are these important for prediction models?

- What are likelihood ratios and how can they be used clinically?

- What are the main study findings? How often did late complications occur in the study population?

- To what degree can the findings be accounted for by:

- How patients were selected, excluded, or lost to follow-up?

- How the main variables were measured?

- Confounding (false attribution of causality because 2 variables discovered to be associated actually are associated with a 3rd factor)?

- Chance?

- Time of year?

- Physicians' interpretation of overall assessment/"gut feeling"/severity?

- How comparable is the study sample to your practice/patient population?

- What contextual factors are important for interpreting the findings?

- How actionable are the results of the prediction model? Would you use the risk score in your clinical practice? Would you consider changing treatment recommendations based on this study? Closer follow-up? Antibiotic prescribing?

- Is this study applicable to areas with more limited medical resources?

- What researchable questions remain?

- Could (or should) this research be replicated? What barriers would prevent similar studies from achieving the same power?

\section{References}

1. Stange KC, Miller WL, McLellan LA, et al. Annals Journal Club: It's time to get RADICAL. Ann Fam Med. 2006;4(3):196-197. http:// AnnFamMed.org/cgi/content/full/4/3/196. 